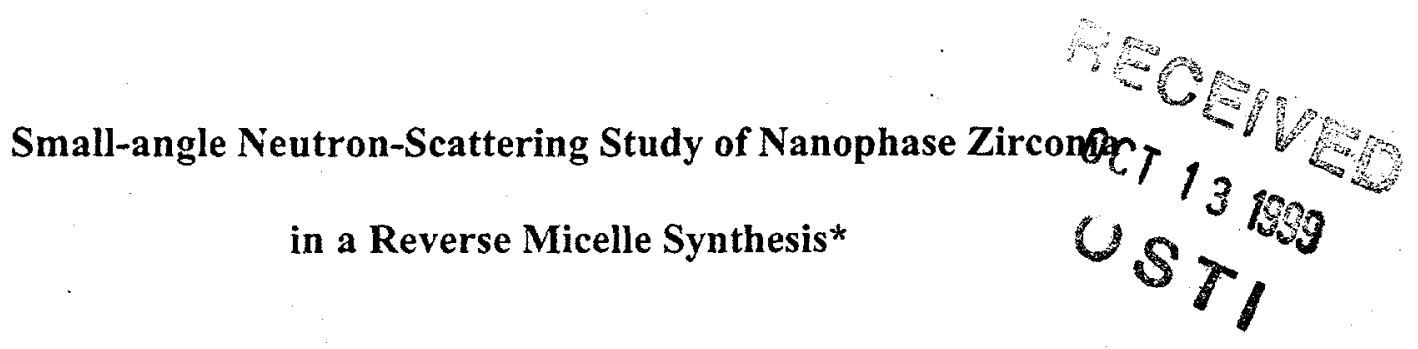

X. Li ${ }^{a, b}$, C.-K. Loong ${ }^{a}$, P. Thiyagarajan ${ }^{a}$, G. A. Lager ${ }^{b}$ and R. Miranda ${ }^{b, c}$

${ }^{a}$ Intense Pulsed Neutron Source Division, Argonne National Laboratory, Argonne, IL 60439

bepartments of Chemical Engineering \& Geoscience, University of Louisville, Louisville, KY 40292

${ }^{\mathrm{C}}$ Chemical and Transport System Division, National Science Foundation, Arlington, VA 22230

\begin{abstract}
The submitted manuscript has been created by the University of Chicago as Operator of Argonne National Laboratory ("Argonne") under Contractor No. W-31-109-ENG-38 with the U.S. Department of Energy. The U.S. Government retains for itself, and others acting on its behalf, a paid-up, nonexclusive, irrevocable worldwide license in said article to reproduce, prepare derivative works, distribute copies to the public, and perform publicly and display publicly, by or on behalf of Government.
\end{abstract}

An invited paper to be presented at the $11^{\text {th }}$ International Conference on Small Angle Scattering, Brookhaven National Laboratory, NY May 17-20, 1999

To be published in Journal of Applied Crystallography

*Work supported by U. S. Department of Energy, BES, contract No. W-31-109-ENG-38

Corresponding author:

Chun Loong

IPNS, Bldg. 360

Argonne National laboratory

9700 S. Cass Ave

Argonne, IL 60439-4814

U.S.A.

The submitted manuscript has been created by the University of Chicago as Operator of Argonne National Laboratory ("Argonne") under Contract No. W-31-109-ENG-38 with the U.S. Department of Energy. The U.S

Tel: $630-252-5596$

FAX: 630-252-4163

Email: ckloong@anl.gov Government retains for itself, and others acting on its behalf, a paid-up, nonexclusive, irrevocable worldwide license in said article to reproduce, prepare derivative works, distribute copies to the public, and perform publicly and dispiay publicly, by or on behalf of the Government. 


\section{DISCLAIMER}

This report was prepared as an account of work sponsored by an agency of the United States Government. Neither the United States Government nor any agency thereof, nor any of their employees, make any warranty, express or implied, or assumes any legal liability or responsibility for the accuracy, completeness, or usefulness of any information, apparatus, product, or process disclosed, or represents that its use would not infringe privately owned rights. Reference herein to any specific commercial product, process, or service by trade name, trademark, manufacturer, or otherwise does not necessarily constitute or imply its endorsement, recommendation, or favoring by the United States Government or any agency thereof. The views and opinions of authors expressed herein do not necessarily state or reflect those of the United States Government or any agency thereof. 


\section{DISCLAIMER}

Portions of this document may be illegible in electronic image products. Images are produced from the best available original document. 


\title{
Small-angle Neutron-Scattering Study of Nanophase Zirconia in a Reverse Micelle Synthesis
}

\author{
X. Li ${ }^{\text {a.b.*, }}$ C.-K. Loong ${ }^{a}$. P. Thiyagarajan ${ }^{a}$, G. A. Lager ${ }^{b}$ and R. Miranda ${ }^{\text {b.c }}$ \\ ${ }^{a}$ Intense Pulsed Neutron Source Division, Argonne National Laboratory, Argonne, Il 60439 \\ ${ }^{b}$ Departments of Chemical Engineering \& Geoscience, University of Louisville, \\ Louisville, KY 40292 \\ ${ }^{c}$ Chemical and Transport System Division, National Science Foundation, Arlington, VA 22230
}

\begin{abstract}
Nanophase zirconia particles are synthesized by mixing two reverse micelle solutions containing the precursor salt $\mathrm{ZrOCl}_{2}$ and the base $\mathrm{NH}_{4} \mathrm{OH}$. The primary reverse micelle solution consists of AOT, toluene and water. The reverse micelle structure of four solutions as a function of $w$ (the molar ratio of [water]/[AOT]) is characterized by small-angle neutron scattering at room temperature. With the addition of $\mathrm{ZrOCl}_{2}$ and $\mathrm{NH}_{4} \mathrm{OH}$ into the water pools, the reverse micelle sizes decrease as compared to those in the $\mathrm{D}_{2} \mathrm{O} / \mathrm{AOT} / \mathrm{C}_{6} \mathrm{D}_{5} \mathrm{CD}_{3}$ primary system. The mixed microemulsions contain reverse micelle sizes that fall between the values of the pre-mixed solutions. All the reverse micelles exhibit uniform size and spherical shape. The effect of concentration of inorganic salt precursor in the water pools on the reverse micelle structure is also studied.
\end{abstract}

\footnotetext{
- Corresponding author: Xiaohe Li, email: xli@anl.gov, FAX: 630-252-4163
} 


\section{Introduction}

Nanophase materials exhibit unique physicochemical properties such as abnormal optical absorption due to quantum size effects, superplasticity due to the uniform morphology, lower sintering and melting temperatures due to mass transport between nanoparticles (Goldstein, 1997). The high surface area of nanophase zirconia is an important factor favoring its utilization as catalysts and catalyst supports. It is widely used in industrial processes such as $\mathrm{NO}_{\mathrm{X}}$ reduction, methanol synthesis, automotive exhaust treatment, isomerization and alkylation (Yamaguchi, 1994). Among many low-temperature synthesis routes for preparing nanophase materials, the reverse micelle or microemulsion method has attracted keen attention from researchers. This method provides a means to compartmentalize the chemical reactions between the metal-ion containing precursor and reagent within nanometer-size water droplets, permitting, in principle, the nucleation and formation of nanoparticles in a controlled manner.

Masui et al. (1997) reported that nano-sized, $\mathrm{Al}_{2} \mathrm{O}_{3}$-supported $\mathrm{CeO}_{2}-\mathrm{ZrO}_{2}$ catalysts prepared by a microemulsion method can provide a $\mathrm{CO}$ oxidation activity much higher than those for the same catalyst prepared by the conventional co-precipitation method. It was shown that the size of the palladium particles prepared by the microemulsion method was remarkably small and uniform (Kim et al., 1997). For hydrogenation of carbon monoxide, the catalytic activity of zirconiasupported palladium catalysts prepared by this method is much higher than that of the catalysts prepared by impregnation. These investigators focused their studies on the catalytic performance of the final products, and others (Kawai et al., 1996, Yang et al., 1996, Fang et al., 1997, Wang et al., 1997) measured the particle size of the zirconia gels prepared by reverse micelle method using various surfactants. To the best of knowledge, characterization of the reverse micelle 
structure in a microemulsion prior to nucleation of nanoparticles has not been reported for the zirconia system.

We have studied the formation and growth of $\mathrm{Zr}$-containing colloids in microemulsions, organic sols and aqueous solutions as well as the crystal phases and microstructure of zirconia gels using a variety of experimental techniques including small-to-wide-angle neutron and $\mathrm{x}$-ray scattering, electron microscopy, isotherm adsorption measurements and thermal analysis. In this paper, we report the synthesis of nanophase zirconia by microemulsion based on a $D_{2} \mathrm{O} / \mathrm{AOT} / \mathrm{C}_{6} \mathrm{D}_{5} \mathrm{CD}_{3}$ system and the characterization of the reverse micelle structure by time-of-flight small-angle neutron scattering (SANS). The effects of water/AOT ratio, content of inorganic solutes, and chemical reaction with ammonium hydroxide on the reverse micelle structure are investigated.

\section{Experimental}

\section{A. Synthesis}

Sodium bis(2-ethylhexyl) sulphosuccinate (AOT) (Aldrich, without further purification) was first dissolved in toluene (Mallinckrodt Chemical) to form a 0.1 M solution. Purified water (Millipore system) was then added to form the primary microemulsions with selective molar ratios $\mathrm{w}=$ [water]/[AOT]. To obtain the $\mathrm{Zr}$-containing microemulsions, appropriate amounts of $0.2 \mathrm{M}$ $\mathrm{ZrOCl}_{2}$ (Alfa) aqueous solution corresponding to a specific $\mathrm{w}$ value was added into the AOT/toluene solution. Likewise, accurate amounts of $22 \mathrm{wt} \%$ ammonium hydroxide aqueous solution (Alfa) was injected into AOT/toluene to achieve the same w values. All solutions were stirred continuously during the formation of microemulsion. Subsequently, the $\mathrm{Zr}-$ and ammonium-containing microemulsions of the same $\mathrm{w}$ value were mixed together. The mixed solutions were stirred for a certain time to ensure equilibrium.

\section{B. Small Angle Neutron Scattering Measurements}


The neutron experiments were carried out using the time-of-flight Small-Angle Neutron Diffractometer (SAND) at the Intense Pulsed Neutron Source of Argonne National Laboratory. The SAND beamline aims at a $20 \mathrm{~K}$ solid-methane neutron moderator/target assembly, providing larger fluxes of long-wavelength neutrons. Fixed moderator-to-sample and sample-to-detector distances of 7 and $2 \mathrm{~m}$, respectively, are sufficient to cover a wavevector (q) of 0.003-1.0 $\AA^{-1}$ using an gas-filled area detector and time-of-flight technique $(q=4 \pi \sin \theta / \lambda$, where $\theta$ is half the scattering angle, $\lambda$ is the wavelength of the neutron). The q-resolution (root-mean-square deviation) varying from about 0.001 to $0.012 \AA^{-1}$ over the q-range of $0.007-0.03 \AA^{-1}$ is exceedingly adequate for the present experiment. In order to obtain better scattering contrast between the water pool and the solvent, and to reduce incoherent-scattering background, $\mathrm{D}_{2} \mathrm{O}$ (Alfa, 99\% d-atom) and $\mathrm{C}_{6} \mathrm{D}_{5} \mathrm{CD}_{3}$ (Alfa, 98\% d-atom) were used in the measurements. Four types of microemulsions each with different $w$ values, i.e., $D_{2} \mathrm{O} / \mathrm{AOT} / \mathrm{C}_{6} \mathrm{D}_{5} \mathrm{CD}_{3}$, $\left(\mathrm{ZrOCl}_{2}+\mathrm{D}_{2} \mathrm{O}\right) / \mathrm{AOT} / \mathrm{C}_{6} \mathrm{D}_{5} \mathrm{CD}_{3},\left(\mathrm{NH}_{4} \mathrm{OH}+\mathrm{H}_{2} \mathrm{O}\right) / \mathrm{AOT} / \mathrm{C}_{6} \mathrm{D}_{5} \mathrm{CD}_{3}$, and the mixture of the last two solutions, were characterized by SANS at room temperature. It should be mentioned that $0.2 \mathrm{M}$ $\mathrm{ZrOCl}_{2}$ solution was prepared by $\mathrm{D}_{2} \mathrm{O}$ instead of $\mathrm{H}_{2} \mathrm{O}$, but the $\mathrm{NH}_{4} \mathrm{OH}$ solution was not deuterated. A sample was injected into a Suprasil (quartz) planar cell of a thickness of $2 \mathrm{~mm}$ and a volume of $0.7 \mathrm{ml}$. The sample cell was sealed in order to avoid solvent evaporation and contamination. The data sets were corrected for instrumental background, scattering from the Suprasil cell, sample transmission and detector sensitivity. The intensities were calibrated to absolute scale by using a silica standard (Thiyagarajan et al., 1997).

\section{Model and data analysis}

Reverse Micelles are known to form in the water/AOT/toluene system over the water/AOT molar ratio of $0 \cdot \mathrm{w} \cdot 20$, although detailed SANS studies have not been reported. A reverse 
micelle, imbedded within the toluene solvent (matrix), consists of a water pool confined by a spherical shell of AOT molecules with their polarized head-groups oriented in the AOT-water interfacial region and their hydrocarbon tails pointing outward. The small-angle scattering intensities arise from inhomogeneity due to the scattering-density difference (contrast) between the reverse micelles and the matrix. Therefore, in general, the SANS profile can be expressed as (Teixeira, 1988):

$$
I(q)=I_{0} P(q) S(q)
$$

where $P(q)$ is a form factor describing the internal structure of the reverse micelle, $S(q)$ is an inter-particle structure factor describing the nature of interactions between the micelles, and $\mathrm{I}_{0}$ is forward-scattering $(\mathrm{q}=0)$ intensity proportional to the scattering-density contrast and the number density of the reverse micelles. In the present case the micelle concentrations are sufficiently dilute to neglect the inter-micelle interaction, consequently, $S(q)=1$.

It follows that quantitative information regarding the structure of the reverse micelles can be obtained by fitting the data to a structural model of $\mathrm{P}(\mathrm{q})$. We used a spherical core-shell model that is commonly used for reverse micelles (Pedersen, 1997),

$$
P(q)=\left\{\frac{4 \pi R_{0}^{3}}{3}\left(\rho_{m}-\rho_{p}\right)\left\{3\left[\frac{\sin \left(q R_{0}\right)-q R_{0} \cos \left(q R_{0}\right)}{\left(q R_{0}\right)^{3}}\right]\right\}+\frac{4 \pi R^{3}}{3}\left(\rho_{p}-\rho_{D}\right)\left\{3\left[\frac{\sin (q R)-q R \cos (q R)}{(q R)^{3}}\right]\right\}\right\}^{2}
$$

In this equation, $R_{0}$ and $R$ are the radii of the entire micelle and the water pool, respectively. $\rho_{m}$, $\rho_{\mathrm{p}}$ and $\rho_{\mathrm{D}}$ are the scattering-length densities of toluene, AOT and water, respectively.

The above formalism does not account for the different sizes of the reverse micelles in a solution. In order to include this effect, the contributions from $P(q)$ of different radii are summed according to a log-normal distribution. An additional parameter, $\sigma=$ the standard deviation of 
the log-normal distribution, was introduced (Loong et al., 1997). $\sigma=1$ corresponds to a monodisperse system where all the reverse micelles are of the same size.

\section{Results and discussion}

Figure 1 shows the observed SANS profiles in terms of log-I-versus-log-q plots for the four reverse micelle systems with $w$ fixed at $10:$ i) $D_{2} O / A O T / C_{6} D_{5} C D_{3}$, ii) $\left(\mathrm{ZrOCl}_{2}+\mathrm{D}_{2} \mathrm{O}\right) / \mathrm{AOT} / \mathrm{C}_{6} \mathrm{D}_{5} \mathrm{CD}_{3}$, iii) $\left(\mathrm{NH}_{4} \mathrm{OH}+\mathrm{H}_{2} \mathrm{O}\right) / \mathrm{AOT} / \mathrm{C}_{6} \mathrm{D}_{5} \mathrm{CD}_{3}$, and iv) the mixture of ii) and iii). The shape is typical to all the observed profiles. The leveling-off of the data in the low-q end indicates the independent, non-interactive nature of the reverse micelles in the dilute solutions. The fall-off of the data followed by a second maximum in the high-q end is clearly seen. Such a behavior is typical for colloids of a certain size and it also indicates that the data quality is not affected by the instrumental resolution. The results of the fits by the shell-core model are shown in Fig. 1. As it can be seen, the fitting to the data by the shell-core model is satisfactory. Similarly good fits were obtained for all the data although the $\chi^{2}$ values and the uncertainties are somewhat larger for iii) due to the weaker coherent-scattering of $\mathrm{NH}_{4} \mathrm{OH}+\mathrm{H}_{2} \mathrm{O}$ and higher incoherent-scattering background.

The average size of the micelles is characterized by the q-value at the onset of the fall-off of the data, which are denoted by the arrows in Fig. 1. A small $q$ onset value implies large size. The data for $w=10$ show that the size of the micelles decreases as $\mathrm{ZrOCl}_{2}$ or $\mathrm{NH}_{4} \mathrm{OH}$ is added into the primary solution. The size reduction is largest for $\mathrm{ZrOCl}_{2}$, smallest for $\mathrm{NH}_{4} \mathrm{OH}$, and intermediate for mixed $\left(\mathrm{ZrOCl}_{2}+\mathrm{NH}_{4} \mathrm{OH}\right)$. This trend is observed over the entire range of $\mathrm{w}$ in this study. Figure 2 shows the overall radii of the reverse micelles as a function of $w$ for the four systems obtained from a least-squares fitting of the data. The standard deviation of the log- 
normal distribution of micelle sizes was found to be between 1 and 1.1 for all the solutions. Therefore, the present systems can be regarded as microemulsion containing reverse micelles of uniform sizes.

The nature of the water pool of reverse micelles in water/AOT/organic solvent has been investigated by many methods. (Luisi et al., 1988, Kon-No, 1997) Cumulative evidence points to the existence of two water populations in the pool. Near the micelle wall the water molecules are highly immobilized ('bound') by their association with the surfactant polar head groups and the counter-ions. In the inner region of the pool the water molecules behave like bulk ('free') water. At low water content ( $w \lesssim 7$ ), the pool is small, containing only the 'bound' water. As the water content increases ( $w \geqslant 7$ ), the size of the water pool increases substantially, admitting 'free' water into the inner region.(Foley et al., 1997) Our data of $\mathrm{D}_{2} \mathrm{O} / \mathrm{AOT} / \mathrm{C}_{6} \mathrm{D}_{5} \mathrm{CD}_{3}$ (Fig. 2) support this notion - the sharp increase of the micelle radius at $w$ larger than 7.5 is due to the expansion of the water pool.

When $\mathrm{ZrOCl}_{2}$ is dissolved in water, hydrolyzed zirconium tetramers $\left[\mathrm{Zr}_{4}(\mathrm{OH})_{8}\left(\mathrm{H}_{2} \mathrm{O}\right)_{16}\right]^{8+}$ are formed under acidic condition. Previous X-ray studies showed that the $4 \mathrm{Zr}$ ions are arranged at the corners of a square and bridged by $2 \mathrm{OH}$ ions along each edge. Additionally, each $\mathrm{Zr}$ is bound to $4 \mathrm{H}_{2} \mathrm{O}$ molecules, and $8 \mathrm{Cl}^{-}$ions are held by electrostatic forces (Muha and Vaughan, 1960). The overall dimension of the tetramer is about $9 \AA$. If the $\mathrm{pH}$ is increased by adding $\mathrm{NH}_{4} \mathrm{OH}$, for example, rapid polymerization of the tetramers occurs, followed by aggregation and eventual precipitation of zirconium hydroxide particles. The confinement of the $\mathrm{Zr}$-tetramers within uniform, nano-meter size reverse micelles will, in principle, retard the chemical reaction with the basic reagent, thereby producing uni-size, ultrafine particles. Fig. 2 shows that when 0.2 
$\mathrm{M} \mathrm{ZrOCl} 2$ aqueous solution is used instead of pure water, the micelles retain a substantially smaller size as $\mathrm{w}$ varies from 2.5 to 20 . This behavior implies even the water-to-AOT molar ratio is increasing, almost all the water molecules are utilized to form the hydration shell around the surfactant and $\mathrm{Zr}$-containing species. Furthermore, the presence of the $\mathrm{Zr}^{4+}$ ions (and the $\mathrm{Cl}^{-}$ counter-ions) in the micelles appear to interact with the AOT head groups, which effectively modifies the electrostatic interaction with the water molecules.

The size of the reverse micelles with added $\mathrm{NH}_{4} \mathrm{OH}$ is also smaller than that of pure water but is larger than that of added $\mathrm{ZrOCl}_{2}$, see Fig. 2. This suggests similar association of the $\mathrm{NH}_{4}{ }^{+}$and $\mathrm{OH}^{-}$ions with the surfactant but less effective in altering the AOT-water interaction. Therefore, when reverse micelles containing separately $\mathrm{ZrOCl}_{2}$ and $\mathrm{NH}_{4} \mathrm{OH}$ are mixed together presumably forming new micelles, the size will fall in between the values of the pre-mixed micelles. This is indeed observed in the present experiment (Fig. 2).

Under the scenario of a strong interaction between the hydrolyzed $\mathrm{Zr}$-ions and the surfactant, it is of interest to investigate the effect of Zr-ion concentration on the structure of the reverse micelles. Figure 3 shows the SANS profiles of $\left(\mathrm{ZrOCl}_{2}+\mathrm{D}_{2} \mathrm{O}\right) / \mathrm{AOT} / \mathrm{C}_{6} \mathrm{D}_{5} \mathrm{CD}_{3}$ at a fixed $\mathrm{w}$ of 15 with the $\mathrm{Zr}$ concentration varying from 0.1 to $1.0 \mathrm{M}$. As expected, monodisperse spherical reverse micelles are formed. The radius of the micelles obtained from the fits is found to decrease slightly from 23 to $19 \AA$ as increasing solute concentration from 0.1 to $1.0 \mathrm{M}$. This finding support qualitatively the idea that more $\mathrm{Zr}$ ions are bound to the surfactant molecules thereby modifying the surface energy available to accommodate water molecules into the pool. This result is consistent with a systematic study of the structural changes of reverse micelles induced by added solutes by Pileni, (1989). 


\section{Conclusion}

The reverse micelle method has been applied for syntheses of a rich variety of nanophase materials. An understanding of the structure and dynamics of reverse micelles with respect to the processing parameters and product properties will greatly enhance the potential of this method. We have applied the technique of SANS to characterize the structure of reverse micelles in the primary water/AOT/toluene system and its response to addition of $\mathrm{ZrOCL}_{2}$ and $\mathrm{NH}_{4} \mathrm{OH}$. The monodisperse, spherical micelles were characterized by fitting the data with a core-shell model. A trend of interactions between the hydrolyzed ions with the AOT surfactant molecules, which affect the size of the water pool was identified. Given the simplicity of the shell-core model, the short-range order of the hydrolyzed $\mathrm{Zr}$-ion complexes, whether there are tetramers or octamers as evidenced in a recent small-angle $\mathrm{x}$-ray scattering study of aqueous solutions (Singhal et al., 1996), cannot be derived from the present data. Undoubtedly, more studies by SANS and other methods are required to clarify the nature of formation of reverse micelles and their interactions in the microemulsion.

\section{Acknowledgement}

We would like to thank $\mathrm{K}$. Takeuchi and $\mathrm{D}$. Wozniak for their assistance in the sample preparation and data collection. Work performed at Argonne National Laboratory is supported by the U. S. DOE-BES under the contract No. W-31-109-ENG-38. 


\section{References}

Fang, J., Wang, J., Ng, S.-C., Chew, C.-H. and Gan, L.-M. (1997) NanoStructured Materials, 8, 400-505.

Foley, M. S. C., Beeby, A., Parker, A. W., Bishop, S. M. and Phillips, D. (1997) Journal of Photochemistry and Photobiology, B 38, 18-24.

Goldstein, A. N. (Ed.) (1997) Handbook of Nanophase Materials, Marcel Dekker, New York.

Kawai, T., Fujino, A. and Kon-No, K. (1996) Colloids and Surfaces, A 109, 245-253.

Kim, W.-Y., Hanaoka, T., Kishida, M. and Wakabayashi, K. (1997) Applied Catalysis A: General, 155, 283-289.

Kon-No, K. (1997) In Structure-Performance Relationships in Surfactants(Eds, K.Esumi and Ueno, M.) Marcel Dekker, Inc., New York, pp. 551-582.

Loong, C.-K., Thiyagarajan, P., Richardson, J., J. W., Ozawa, M. and Suzuki, S. (1997) Journal of Catalysis, 171, 498-505.

Luisi, P. L., Giomini, M., Pileni, M. P. and Robinson, B. H. (1988) Biochimica et Biophysica Acta, 947, 209-246.

Masui, T., Fujiwara, K., Machida, K.-I. and Adachi, G.-Y. (1997) Chemistry of Materials, 9, 2197-2204.

Muha, G. M. and Vaughan, P. A. (1960) Journal of Chemical Physics, 33, 194-199.

Pedersen, J. S. (1997) Advances in Colloid and Interface Science, 70, 171-210.

Pileni, M. P. (1989) In Structure and Reactivity in Reverse Micelles(Ed, Pileni, M. P.) Elsevier Science Publishers B. V., Amsterdam, pp. 44-53.

Singhal, A., Toth, L. M., Lin, J. S. and Afholter, K. (1996) Journal of American Ceramic Society, 118, 11529-11534. 
Teixeira, J. (1988) Journal of Applied Crystallography, 21, 781-785.

Thiyagarajan, P., Epperson, J. E., Crawford, R. K., Carpenter, J. M., Klippert, T. E. and Wozniak, D. G. (1997) Journal of Applied Crystallography, 30, 208-293.

Wang, J., Ee, L. S., Ng, S. C., Chew, C. H. and Gan, L. M. (1997) Materials Letters, 30, 119 124.

Yamaguchi, T. (1994) Catalysis Today, 20, 199-218.

Yang, C., Hong, B. and Chen, J. (1996) Powder Technology, 89, 149-155. 
Figure Captions:

Figure 1. The SANS profiles of reverse micelle solutions at water/AOT molar ratio $=10$ : (a) $\mathrm{D}_{2} \mathrm{O} / \mathrm{AOT} / \mathrm{C}_{6} \mathrm{D}_{5} \mathrm{CD}_{3}$, (b) $\left(\mathrm{ZrOCl}_{2}+\mathrm{D}_{2} \mathrm{O}\right) / \mathrm{AOT} / \mathrm{C}_{6} \mathrm{D}_{5} \mathrm{CD}_{3}$, (c) $\left(\mathrm{NH}_{4} \mathrm{OH}+\mathrm{H}_{2} \mathrm{O}\right) / \mathrm{AOT} / \mathrm{C}_{6} \mathrm{D}_{5} \mathrm{CD}_{3}$, and (d) the mixture of (b) and (c). For clarity, the absolute intensities of data sets a, b, c, and d were multiplied by $1,0.1,10$, and 3 , respectively. The uncertainties of the data points are comparable to the size of the symbols except for the low- and high-q ends where selective errors are given. The curves are the results of least-squares fits of the data to a shell-core model. The position of the arrows is inversely proportional to the micelle size. They show decreasing sizes in the order of $a, d, c, b$.

Figure 2. The radius of the reverse micelles against the water/AOT molar ratio. The lines are guides to the eye.

Figure 3. The SANS profiles of reverse micelle solutions of $\left(\mathrm{ZrOCl}_{2}+\mathrm{D}_{2} \mathrm{O}\right) / \mathrm{AOT} / \mathrm{C}_{6} \mathrm{D}_{5} \mathrm{CD}_{3}$ with different $\mathrm{ZrOCl}_{2}$ concentrations. For clarity, the absolute intensities of data sets $\mathrm{a}, \mathrm{b}, \mathrm{c}, \mathrm{d}$, and e were multiplied by $50,15,6,3$, and 1 , respectively. The curves are the results of least-squares fits of the data to a shell-core model. 


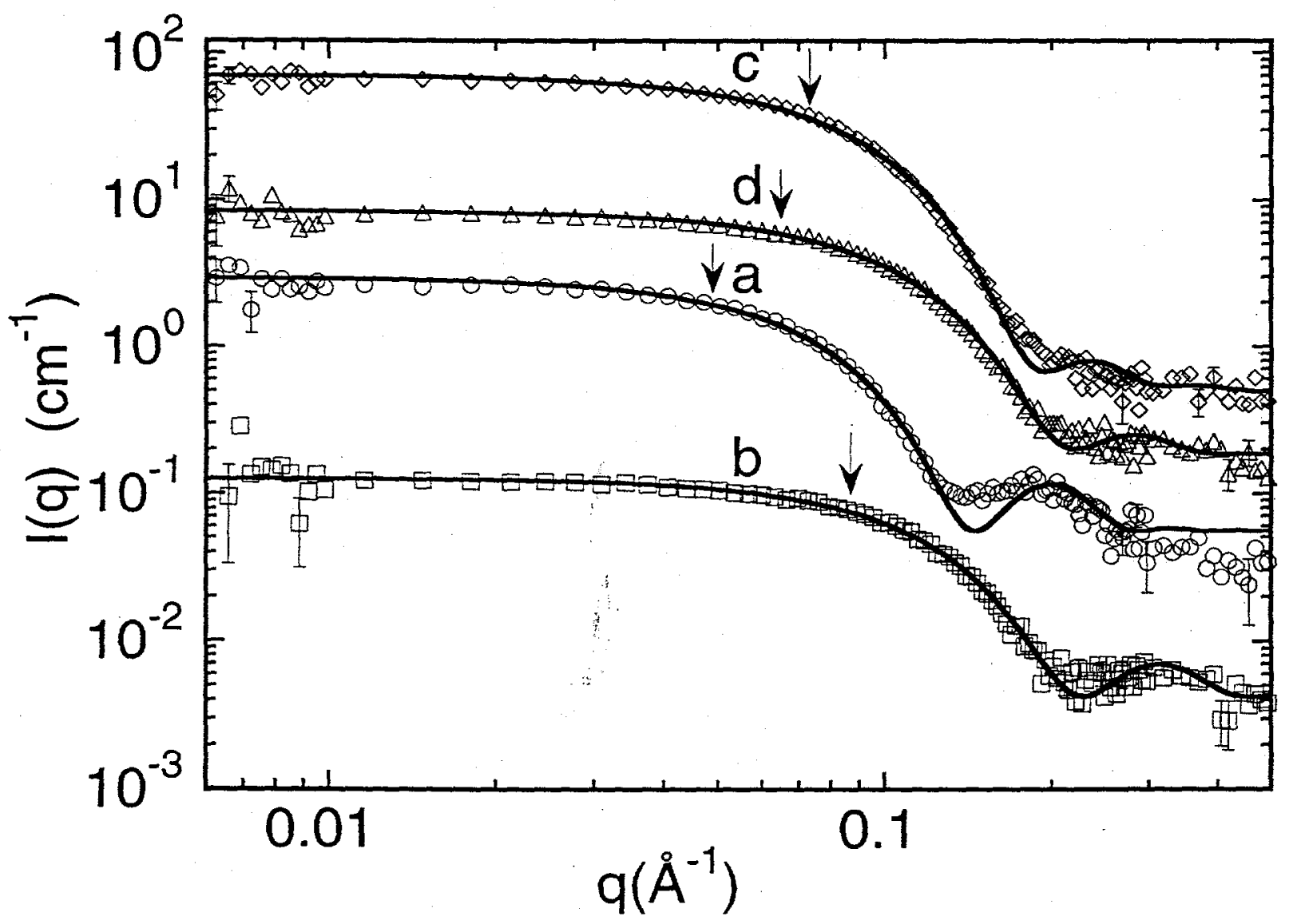

Fig. 1., X. Li, et al, "Small-angle Neutron-Scattering study...". 


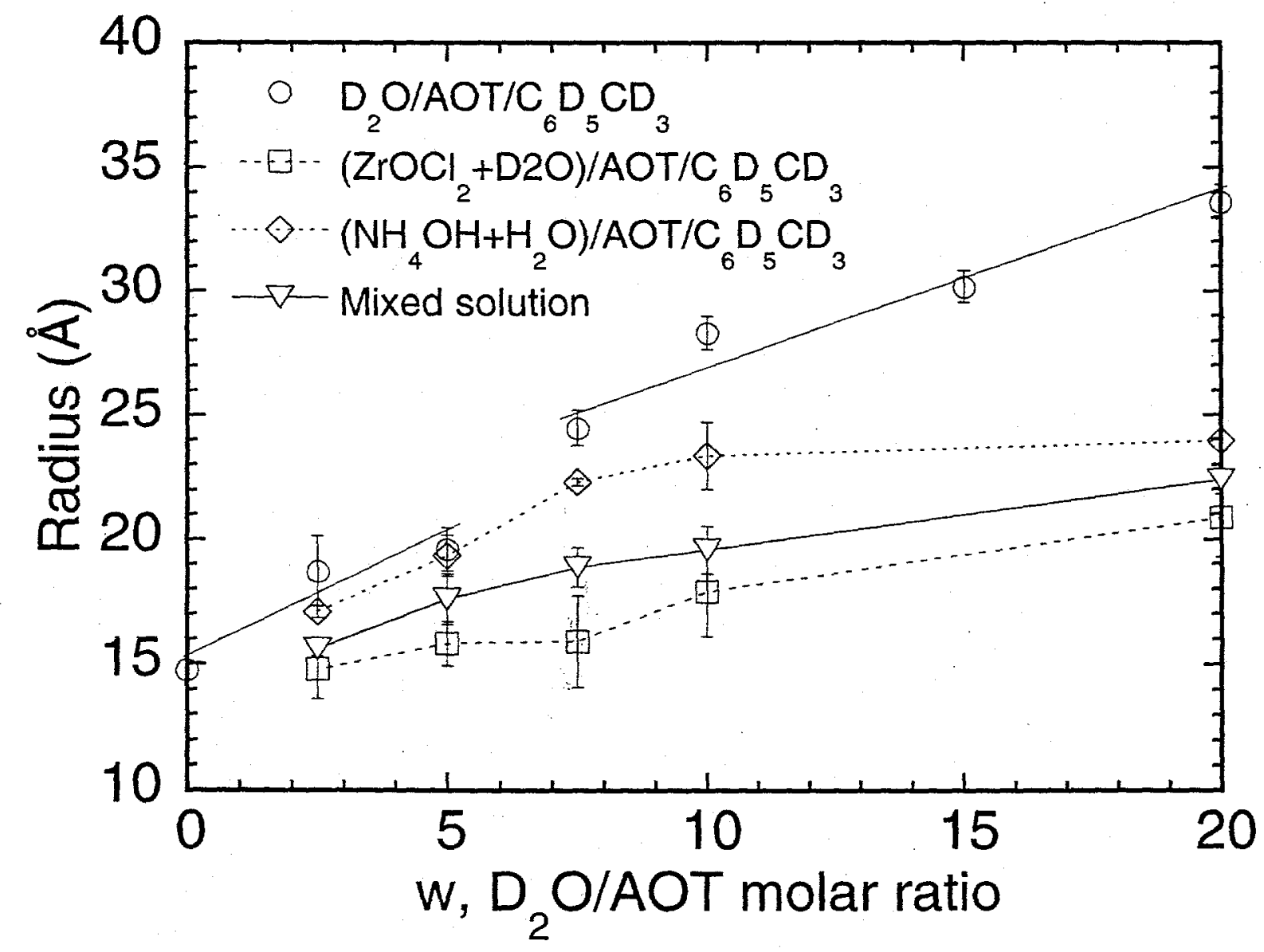

Fig. 2., X. Li, et al, "Small-angle Neutron-Scattering study..."." 


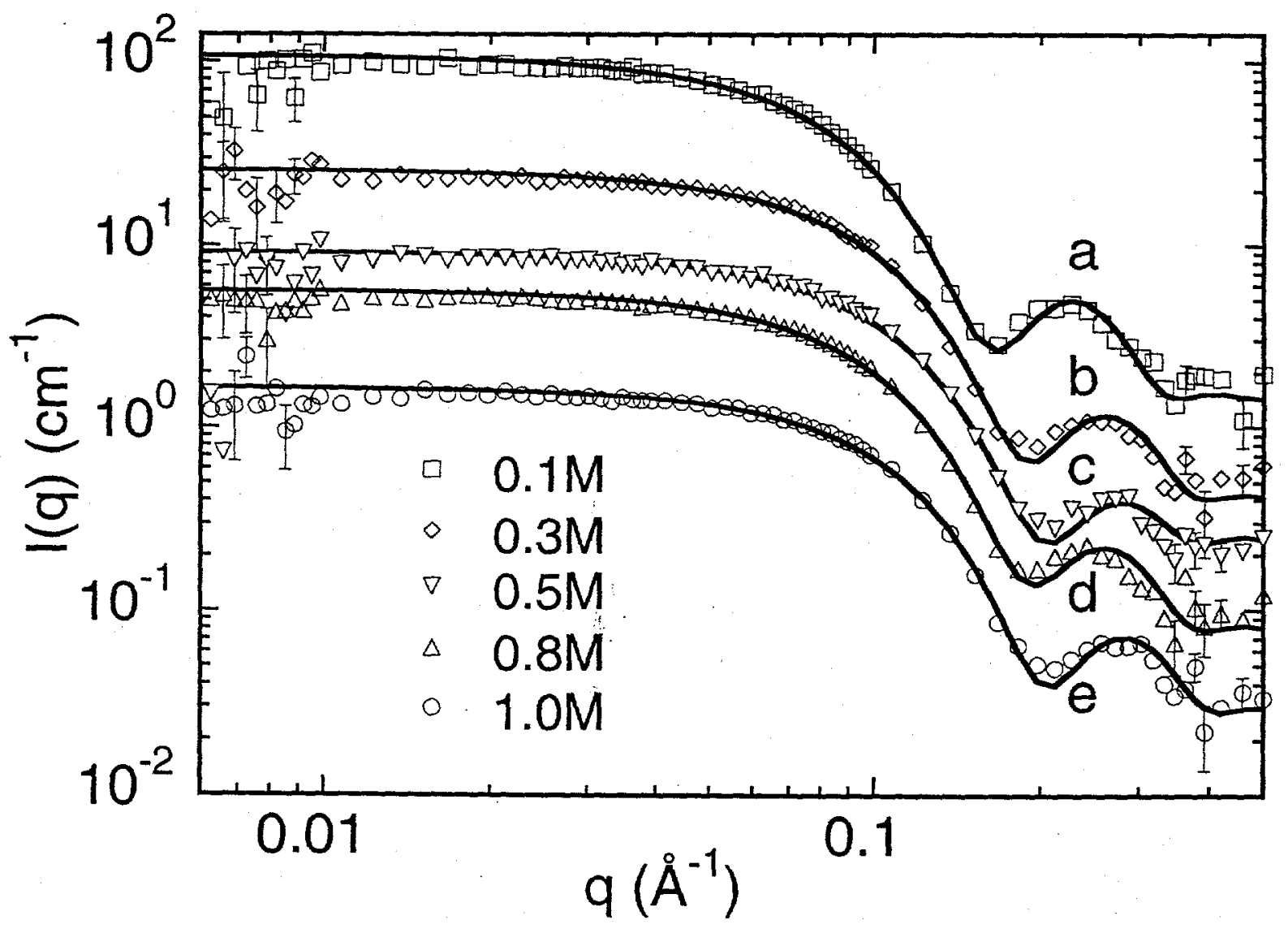

Fig. 3., X.Li, et al, "Small_angle Neutron-Scattering study ...". 